\title{
CARTOGRAFIA AFETIVA DA EXPERIÊNCIA ESCOLAR: PENSANDO EM ESTRATÉGIAS DE ENFRENTAMENTO DOS IMPACTOS DA COVID-19 NA EDUCAÇÃO
}

\section{AFFECTIVE CARTOGRAPHY OF THE SCHOOL EXPERIENCE: THINKING OF STRATEGIES FOR COPING WITH THE IMPACTS OF THE COVID-19 ON EDUCATION}

\author{
Beatriz Paz ${ }^{51}$ \\ Marina Bueno 52
}

\begin{abstract}
Resumo
A pandemia da COVID-19 nos impôs um contexto mundial causador de uma série de perturbações, tais como: luto, medo, dificuldades materiais, angústias, letargia, impotência, incertezas sobre o futuro, dentre outras. Tal contexto nos convoca ainda mais a buscar estratégias de cuidado e proteção psicossocial, de modo a mitigar os efeitos da crise sanitária. Este trabalho pretende realizar uma discussão em torno da Cartografia Afetiva, enquanto método de pesquisa e intervenção que, pautada num certo modo de olhar, escutar, acolher e agir com (ou intervir sobre) o que se passa em cada um e deste no encontro com o outro, pode vir a contribuir para a construção de um cuidado colaborativo na educação no contexto da pandemia da COVID-19. A pertinência do método cartográfico como estratégia de escuta-intervenção no campo educacional aqui debatida é fruto das análises feitas a partir de um projeto que foi desenvolvido em 2019 em escolas públicas da rede municipal de educação do Rio de Janeiro.
\end{abstract}

Palavras-chave: Pandemia. Cartografia. Educação.

\section{Abstract:}

The COVID-19 pandemic imposed, in a global context, a series of dificulties, such as: mourning, fear, economic difficulties, anguish, lethargy, impotence, uncertainties about the future, among others. This context generates the demand for strategies and

\footnotetext{
${ }^{51}$ Psicanalista. Mestre em Teoria Psicanalítica pelo PPG em Teoria Psicanalítica da Universidade Federal do Rio de Janeiro (2008). Psicóloga concursada da Secretaria Municipal de Educação do Rio de Janeiro atuando no NIAP - Núcleo Interdisciplinar de Apoio às Unidades Escolares. E-mail: beatriz.c.paz@gmail.com Tel: (21) 99943-3940. ORCID: https://orcid.org/0000-0002-6854-8318

52 Assistente social concursada da Secretaria Municipal de Educação do Rio de Janeiro. Doutora pelo Programa de Políticas Públicas e Formação Humana/ PPFH-UERJ (2016), mestre (2009) e graduada (2005) em Serviço Social pela Universidade Federal do Rio de Janeiro. E-mail: marinafbueno@gmail.com Tel: (21) 98872-3913. ORCID: https://orcid.org/0000-0002-5454-2062
} 


\section{RevistAleph}

interventions in the psychosocial care and protection field, in order to try to mitigate the effects of the health crisis. This article intends to bring to the debate the Affective Cartography as a research and intervention method, based on a certain way of looking at, listening to and acting with (or intervening on) what goes through in each individual as well as with his encounter with others. Our perspective is that this method may contribute to the creation of collaborative care in the educational field in the context of the COVID-19 pandemic. The relevance of the cartographic method as a listeningintervention strategy in the educational field discussed here is the result of the analyzes made from a project developed in 2019 in public schools in the municipal educational system in Rio de Janeiro.

Keywords: Pandemic. Cartography. Education.

\section{Introdução}

No mês de março de 2020 as aulas presenciais nas redes pública e privada foram suspensas em muitos estados brasileiros. Tal suspensão ocorreu devido ao crescimento do número de casos da COVID-19, reconhecida como pandemia pela Organização Mundial de Saúde $(\mathrm{OMS})^{53}$. Desde então, foram adotadas no Brasil e em diversos outros países, seguindo as orientações da OMS, uma série de medidas preventivas, como o distanciamento social que inclui restrição de circulação, de contato físico, bem como orientações de cuidados e rituais novos e específicos de higienização e a inclusão da temerosa palavra aglomeração em nosso discurso cotidiano. Em uma sequência de poucos dias, as atividades escolares foram interrompidas e a \#fiqueemcasa ganhou destaque na mídia global.

Apesar da interrupção das aulas presenciais, foram rápidas e frequentes as notícias de movimentos de gestores e demais profissionais da educação que buscaram manter contato com os estudantes por redes sociais e outras tecnologias, na tentativa de acolher e manter algo do vínculo educativo em tempos de distanciamento social. Vale destacar que o acesso ao ambiente virtual não é de forma alguma equânime entre os

\footnotetext{
${ }^{53}$ A OMS decretou pandemia de COVID-19, doença causada pelo novo coronavírus (Sars-Cov-2) em 11 de março de 2020. Disponível em: https://www.unasus.gov.br/noticia/organizacao-mundial-de-saudedeclara-pandemia-de-coronavirus
} 


\section{RevistAleph}

estudantes, suas famílias e profissionais de educação. A questão do acesso à educação na sua totalidade está, mais do que nunca, sendo colocada em discussão pela realidade atual.

Desde muito cedo, logo após o fechamento das escolas, uma pergunta nos salta aos ouvidos: será que estamos dando ao acesso à educação seu devido peso e responsabilidade na rede pública de ensino? Até hoje, passado um ano letivo desde que as escolas públicas municipais do Rio de Janeiro fecharam, esta pergunta ainda retorna, ecoa.

Neste novo cenário, o distanciamento social trouxe enormes desafios e convocou a um ineditismo todos os setores da política pública, e em especial a educação. 0 contexto se mostrou extremamente fluido e diversas questões como a permanência das medidas de distanciamento social juntamente com outras de abertura flexível, permanecem ainda em aberto. Como sociedade e como educadores, temos nos visto diante de um não saber que, se por um lado nos pede uma pausa reflexiva potente, por outro, ainda nos coloca diante da angústia do desconhecido. O que, então, é possível criar a partir deste momento de pausa e que não tenha como efeito a produção de uma paralisia?

Diante destas questões, investimos nossa aposta na Cartografia Afetiva como um método de pesquisa e intervenção que, pautado num certo modo de olhar, escutar, acolher e agir com (ou intervir sobre) o que se passa em cada um e deste no encontro com o outro, pode vir a contribuir para a construção de um cuidado colaborativo na educação no contexto da pandemia da COVID-19.

\section{A Cartografia Afetiva como estratégia de trabalho na educação}

Inserido no âmbito de um conjunto de ações voltadas à valorização do protagonismo e autonomia de crianças e adolescentes da Rede Municipal de Ensino do Rio de Janeiro, o projeto Cartografia Afetiva da experiência escolar foi concebido e executado em caráter interdisciplinar por uma assistente social, uma psicóloga e uma 


\section{RevistAleph}

professora, somando a experiência profissional na política de educação e nossos estudos acadêmicos.

A primeira elaboração da proposta ocorreu no ano de 2017, como desdobramento da pesquisa de doutoramento intitulada Entre os fios de Penélope: uma cartografia das linhas de força que se desenham no cotidiano escolar ${ }^{54}$. Posteriormente, o projeto foi ganhando contornos mais múltiplos, fruto de uma autoria compartilhada entre as profissionais mencionadas, que teve início em 2018 e imprimiu ao projeto traços bastante singulares e próprios dos diferentes campos de saber - serviço social, psicologia e educação $0^{55}$.

É somente no ano de 2019 que o projeto surge como proposta institucional, sendo desenvolvido em duas Unidades Escolares da rede municipal de ensino em caráter piloto, na pretensão de construir ferramentas que seguissem a trilha de uma trajetória de trabalho com a temática do protagonismo juvenil ${ }^{56}$ e, ao mesmo tempo, que pudessem transversalizar as questões pautadas pelos estudantes da rede, tais como: o bullying, a violência de gênero, o racismo, a homofobia, a falta de espaços coletivos de diálogo, a necessidade de discutir temas como sexualidade, depressão, desigualdade social, violência, etc.

\footnotetext{
${ }^{54}$ BUENO, MARINA. Entre os fios de Penélope: uma cartografia das linhas de força que se desenham no cotidiano escolar. Tese de Doutorado submetida ao Programa de Políticas Públicas e Formação Humana - Universidade Estadual do Rio de Janeiro. Rio de Janeiro, 2016.

${ }^{55}$ Para mais informações sobre o projeto, c.f: https://smeniap.wixsite.com/smeniap/singlepost/2019/08/20/cartografia-afetiva-no-espaço-escolar.

${ }^{56}$ No ano de 2018 coordenamos as ações de mobilização dos grêmios estudantis da rede municipal de educação do Rio de Janeiro, contribuindo na formação de 940 diretorias de grêmios eleitos compostos por estudantes da rede. Neste processo, (in)tensionamos um exercício discursivo e em ato de um protagonismo que apostou no estudante como efetivo e principal ator na identificação das questões que precisariam da atenção-suporte dos adultos na transformação escolar. Desde esta experiência e do retorno dos estudantes diante desta convocação à fala através dos grêmios estudantis, firma-se em nós a certeza (já latente em nosso trabalho-aposta) da capacidade e da precisão dos mesmos na identificação de seus desejos, bem como na análise e intervenção necessárias dentro do campo escolar do qual fazem parte. A escrita e o desenvolvimento do projeto Cartografia afetiva da experiência escolar leva os frutos desta experiência em nosso olhar, escuta e intenção de trabalho junto aos estudantes.
} 


\section{RevistAleph}

No que diz respeito às Unidades Escolares nas quais foi desenvolvido o projeto no ano de 2019, ambas estão localizadas em territórios de extrema vulnerabilidade social, com constantes conflitos armados e alto índice de violência local. Elas não serão professoras, somando a experiência profissional na política de educação e nossos estudos acadêmicos.

A primeira elaboração da proposta ocorreu no ano de 2017, como desdobramento da pesquisa de doutoramento intitulada Entre os fios de Penélope: uma cartografia das linhas de força que se desenham no cotidiano escolar ${ }^{57}$. Posteriormente, o projeto foi ganhando contornos mais múltiplos, fruto de uma autoria compartilhada entre as profissionais mencionadas, que teve início em 2018 e imprimiu ao projeto traços bastante singulares e próprios dos diferentes campos de saber - serviço social, psicologia e educação ${ }^{58}$.

É somente no ano de 2019 que o projeto surge como proposta institucional, sendo desenvolvido em duas Unidades Escolares da rede municipal de ensino em caráter piloto, na pretensão de construir ferramentas que seguissem a trilha de uma trajetória de trabalho com a temática do protagonismo juvenil ${ }^{59}$ e, ao mesmo tempo, que pudessem transversalizar as questões pautadas pelos estudantes da rede, tais como: 0 bullying, a violência de gênero, o racismo, a homofobia, a falta de espaços coletivos de

\footnotetext{
${ }^{57}$ BUENO, MARINA. Entre os fios de Penélope: uma cartografia das linhas de força que se desenham no cotidiano escolar. Tese de Doutorado submetida ao Programa de Políticas Públicas e Formação Humana - Universidade Estadual do Rio de Janeiro. Rio de Janeiro, 2016.

58 Para mais informações sobre o projeto, c.f: https://smeniap.wixsite.com/smeniap/singlepost/2019/08/20/cartografia-afetiva-no-espaço-escolar.

${ }^{59}$ No ano de 2018 coordenamos as ações de mobilização dos grêmios estudantis da rede municipal de educação do Rio de Janeiro, contribuindo na formação de 940 diretorias de grêmios eleitos compostos por estudantes da rede. Neste processo, (in)tensionamos um exercício discursivo e em ato de um protagonismo que apostou no estudante como efetivo e principal ator na identificação das questões que precisariam da atenção-suporte dos adultos na transformação escolar. Desde esta experiência e do retorno dos estudantes diante desta convocação à fala através dos grêmios estudantis, firma-se em nós a certeza (já latente em nosso trabalho-aposta) da capacidade e da precisão dos mesmos na identificação de seus desejos, bem como na análise e intervenção necessárias dentro do campo escolar do qual fazem parte. A escrita e o desenvolvimento do projeto Cartografia afetiva da experiência escolar leva os frutos desta experiência em nosso olhar, escuta e intensão de trabalho junto aos estudantes.
} 


\section{RevistAleph}

diálogo, a necessidade de discutir temas como sexualidade, depressão, desigualdade social, violência, etc.

No que diz respeito às Unidades Escolares nas quais foi desenvolvido o projeto no ano de 2019, ambas estão localizadas em territórios de extrema vulnerabilidade social, com constantes conflitos armados e alto índice de violência local. Elas não serão aqui identificadas, seja pela escolha metodológica em não expô-las a análises descontextualizadas, ou mesmo pela consideração de que as situações problematizadas também se apresentam em muitos outros espaços institucionais em que transitamos.

Uma das escolas, localizada na zona sul do Rio de Janeiro, atende estudantes do 60 ao 9o anos do ensino fundamental II. A outra, pertencente à zona norte, atende estudantes do 1 은 a 5 a anos do ensino fundamental I. Ao longo do desenvolvimento do trabalho, podemos identificar que são escolas com um grupo de profissionais, entre corpo gestor, corpo de professores e de funcionários bastante envolvido em criar estratégias possíveis de acolhida dos estudantes, embora ambas escolas sejam atravessadas por uma considerável precariedade institucional, com contexto crônico de falta de professores. Como dito anteriormente, ambas escolas são cotidianamente atravessadas pela violência do território (incluída aí a presença constante de intervenções policiais), o que atinge diretamente a rotina escolar, bem como as narrativas que circulam entre adultos, crianças e adolescentes.

A delimitação destas escolas considerou a taxa de abandono expressa no ano de 2017, bem como os dados dos grêmios estudantis eleitos em 2018. Foram priorizadas as propostas das diretorias executivas dos grêmios estudantis e as sugestões apontadas pelos profissionais das escolas a respeito da necessidade de apoio para impulsionar as ações dos alunos junto aos grêmios.

Neste sentido, o desenvolvimento do projeto Cartografia Afetiva da experiência escolar buscou consolidar formas de abordagem e processos de trabalho que tomam o estudante - seus desejos, expectativas, vinculações e experiências - como uma prioridade para as ações no campo educacional. Pretendeu atuar questionando, 


\section{RevistAleph}

portanto, a ideia de que a adolescência contemporânea seja atravessada por certa apatia e ausência de desejos, o que produz práticas excludentes, ao tomar como pressuposto vigente, o adolescente como sujeito indiferente, irresponsável e até insensível, no sentido de ser pouco tocado ou afetado pelo que o cerca. Compreendendo que a fala se faz presente diante de um ouvinte interessado a ouvir, nossa presença-projeto pretendeu ser esta escuta interessada, a ouvir e refletir-intervir, com os estudantes, sobre suas experiências escolares e seus desejos em relação à escola.

A perspectiva de trabalhar com as experiências dos sujeitos nos conduziu a considerar a advertência feita por Larrosa (2002), de que trata-se de um termo que vem sendo exageradamente utilizado de modo banalizado, para se dizer sobre algo que aconteceu. $\mathrm{O}$ autor sugere que pensemos a experiência não como algo que passa, ou se passa, mas como algo que nos passa, e que vai constituindo nossa forma de habitar o mundo.

O sujeito da experiência é, desse modo, um território de passagem, que máquina afetos, encontros, que se abre a este algo que passou para que ele deixe suas marcas. De que modo as experiências escolares, sociais e afetivas vão constituindo um certo modo de estar e de conceber a escola? O que os alunos têm a dizer sobre isso?

Apesar de inúmeros instrumentos legais e orientações de políticas públicas que se comprometem com a ampliação dos canais de participação e de democratização, estas diretrizes permanecem ainda desafiando nossos saberes, uma vez que os caminhos para efetivá-los não estão dados.

Os pressupostos da cartografia, especificamente aqueles desenvolvidos por autores como Deleuze e Guattari (2005), Passos, Kastrup e Escóssia (2009), Rocha e Aguiar (2003) e Rolnik (1989), entre outros, nos fornecem importantes elementos para a análise dos processos que se realizam no plano da experiência.

Agregando o pesquisar e o intervir, a cartografia vai compondo mapas móveis, que auxiliam na compreensão dos movimentos que produzem a realidade. Em outros 


\section{RevistAleph}

termos, trata-se de efetivar "um trabalho dedicado e pormenorizado de investigar e expor aqueles espaços não óbvios, aqueles vazios (ou seja, aquilo que fica para além do óbvio, do já dito, do já sobejamente conhecido e nomeado)" (FISCHER, 2012, p. 106). Em outros termos, um trabalho que busca escutar as vidas "lá onde, por elas próprias, elas falam" (FOUCAULT, 2003, p. 05), valorizando em seu processo os saberes infames e as práticas menores que normalmente, ofuscadas por um discurso que se coloca como oficial, não encontram canais de expressão.

Foucault chamou de saberes dominados os conteúdos sepultados, desqualificados, menores, muitas vezes situados "abaixo do nível requerido de conhecimento ou de cientificidade" (FOUCAULT, 2004, p. 96), considerando-os elementos fundamentais para o questionamento das práticas que estamos constituindo.

Recorremos aqui fundamentalmente a estes saberes, presentes nas práticas discursivas e não discursivas - no campo da fala, do corpo e do movimento - de adolescentes que ocupam posição marginal em relação ao saber que os adultos representam. São saberes que fogem do discurso institucionalizado, contando outras histórias.

O que se convencionou chamar de metodologia não é aqui assumido como um procedimento acabado, um instrumento universal pronto para ser aplicado. Para a cartografia não há uma determinação prévia dos caminhos, mas sim uma possibilidade de um desenho inicial, que deverá ser revisto e adaptado a cada instante se assim for preciso. Apesar de não buscar predeterminar procedimentos, regras ou protocolos, o trabalho cartográfico proposto consistiu em acompanhar as narrativas de segunda ordem: aquelas que têm maior dificuldades de emergir, trazendo para o campo de análise das práticas escolares tudo aquilo que "faz parte" mas não aparece, dando visibilidade a vínculos, fragilidades e desejos.

Na sua configuração estratégica, o projeto se pautou em ações de diagnóstico, reuniões com profissionais das escolas, entrevistas individuais e oficinas coletivas com grupos de estudantes. Em seu conjunto, tais estratégias buscaram cruzar informações 


\section{RevistAleph}

sobre a estrutura e organização escolar, sobre a trajetória escolar e de vida dos estudantes, os vínculos e afetos estabelecidos nessa vivência e as questões que eles levantavam sobre os encontros e os desencontros na sua relação atual com a escola.

As entrevistas aconteceram no decorrer de todo o projeto desenvolvido nas escolas no ano de 2019 e foram norteadas por um instrumento previamente elaborado, que teve a pretensão de abrir diálogo com cada estudante sobre questões de sua trajetória e expressão de seus saberes. Não pretendemos, neste sentido, coletar dados e informações que servissem a uma pesquisa e análise posterior, mas revisitar experiências, em um contínuo processo de criação e recriação de sentidos. A escolha do local, bem como da profissional que realizaria a entrevista ficava a critério do estudante, como forma de escutarmos, acessarmos e mapearmos neste próprio encontro-escolha, as suas preferências em relação aos espaços da escola e as suas relações, valorizando ainda os vínculos constituídos entre cada estudante e cada integrante da equipe.

Em relação às oficinas, sua organização e realização se pautou nas seguintes estratégias:

- Diversificação dos locais de realização de forma a circular pelos espaços das escolas (sala de leitura, diferentes salas de aula, auditório, quadra, etc.);

- Divisão da turma trabalhada em dois grupos, para exercer maior atenção às coisas ditas, reações e efeitos das discussões, bem como para facilitar a própria condução do encontro;

- Adoção de diferentes formas de expressão, pelo estímulo a diferentes linguagens (desenho, escrita, corpo, música, fala direta, etc.);

- Planejamento dos encontros a partir de eixos do mapeamento, que também se constituíram como provocadores de discussões mais abertas, pautadas pelos estudantes em cada encontro. Foram delimitados quatro eixos, inicialmente com previsão de dois encontros para cada um, podendo se estender conforme demanda do grupo: representação de si e identidade; a escola; o território; temas 


\section{RevistAleph}

recorrentes ${ }^{60}$.

Esse foi um esforço de identificar, integrando momentos individuais e coletivos, as questões que impactam cada estudante, no que diz respeito às suas condições de desenvolvimento e permanência escolar. Nesse processo, foi possível perceber alguns sentidos que cada sujeito-estudante pôde dar para situações vivenciadas, como os motivos de uma reprovação ou de uma transferência de escola no âmbito mais individual, bem como suas análises sobre questões escolares mais amplas como, dentre outras, os motivos da produção do abandono escolar.

Ao mesmo tempo, foi possível mapear os diferentes territórios afetivos dos estudantes (escolar, cultural, identitário, territorial etc.), identificando demandas por intervenções mais direcionadas, como a necessidade de maior suporte nos processos de leitura e escrita, orientação e informação sobre temas específicos (direitos, sexualidade, questão racial etc.) e reflexão coletiva sobre aquilo que aparecia como um problema presente no cotidiano escolar, como bullying, preconceito, racismo etc.

A pesquisa e a intervenção se davam, neste sentido, de forma concomitante, direcionadas a atender nossas expectativas em relação às questões que gostaríamos de cartografar, ao mesmo tempo em que se mantinha uma abertura ao que vinha dos alunos (questões, adesões, recusas...).

\section{Educação e pandemia: mapeando impactos e reinvestindo estratégias}

A previsão de um plano de retomada das atividades escolares - seja de cunho presencial ou remoto, conforme as condições impostas pela pandemia da COVID-1961 demanda de todos nós uma atenção e cuidado com reações, sentimentos e impactos

\footnotetext{
60 Foram organizados encontros que pudessem aprofundar temas recorrentes no decorrer de todo o trabalho, tais como preconceitos, diferenças e suas implicações na convivência diária, bullying, questões raciais, etc.

61 Vale destacar que no momento da escrita do presente artigo, o debate sobre a reabertura das escolas públicas e privadas segue revelando delicados e históricos embates. A SME-RJ em 2021 apresentou um plano de retomada das aulas em um formato híbrido que tem se mostrado bastante limitado em relação
} 


\section{RevistAleph}

causados pelo longo período de distanciamento social na vida dos diferentes sujeitos da comunidade escolar. É recomendado que estejamos atentas (os) aos protocolos e diretrizes das instituições oficiais como OMS, Fiocruz, Ministério da Educação, da Saúde, da Cidadania e as Secretarias Estaduais e Municipais a nível local. Do mesmo modo, é necessário reconhecer as linhas de cuidado e proteção psicossocial das diferentes políticas públicas - em especial saúde e assistência social - localizando as ações escolares enquanto estratégias a elas conectadas.

Nessa direção, alguns impactos da pandemia da COVID-19 e das medidas de distanciamento social já são esperados, considerando as experiências nacionais e internacionais no campo dos desastres e calamidades, bem como as medidas de enfrentamento da pandemia da COVID-19 por outros países, sobretudo os desdobramentos após o fechamento das escolas.

Em recente publicação, a Fiocruz (2020a) aponta alguns desses impactos esperados na população, dos quais destacamos como possíveis desdobramentos para o campo da educação:

- Conflitos interpessoais e comportamentos agressivos e de protesto;

- Dificuldade em retomar rotinas;

- Necessidade de reenquadramento dos projetos de vida;

- Existência de um grande número de pessoas com: depressão, lutos patológicos, estresse pós-traumático, consumo excessivo de álcool e outras drogas,

à realidade do público atendido, posto que toma como pressuposto um acesso e uma alfabetização digital que deixam uma enorme parte dos estudantes fora do acesso à educação. No que diz respeito ao plano de retomada da educação em sua vertente presencial, foi apresentado um protocolo sanitário que pretende garantir segurança à comunidade escolar. No entanto, diante de denúncias diárias de quebras no cumprimento deste mesmo protocolo sanitário, majoritariamente como consequência da pressão dos jogos políticos de poder que caem sobre o corpo docente, permanece em suspenso para nós a viabilidade concreta, com condições de possibilidade de uma abertura e funcionamento das escolas que ultrapasse os documentos e se efetive através de um suporte estrutural que possibilite as medidas de proteção à vida. 


\section{RevistAleph}

comportamento violento, entre outros ${ }^{62}$;

Como forma de atuar nas questões pontuadas, as recomendações para o trabalho no campo da saúde mental e atenção psicossocial (SMAPS) fornecidas pela Fiocruz $^{63}$ indicam a necessidade de ações que promovam o fortalecimento de vínculos, o sentimento de pertencimento, as formas solidárias e participativas a partir de estratégias educacionais, sociais, culturais, artísticas e lúdicas. Junto a isso, recomenda a identificação das demandas que apontam maior risco e vulnerabilidade no que diz respeito ao campo específico de atuação de cada política setorial (demandas no campo da educação, da saúde mental, do sistema de garantia de direitos da criança e do adolescente e dos sistemas de proteção social da assistência social). Importante destacar que tais cuidados podem contribuir para a diminuição do agravamento dos quadros esperados e para uma possível reorganização e um reinvestimento subjetivos.

Tais orientações vão ao encontro dos pressupostos do projeto Cartografia Afetiva da experiência escolar, sobretudo no que diz respeito a sua pretensão de favorecer as condições de vinculação, de pertencimento e o desejo em relação à escola, ao buscar ampliar os canais de acolhimento e escuta, exercendo atenção, validando o que é dito ou expresso de diferentes formas pelos estudantes e demais sujeitos do espaço escolar.

O enfrentamento dos desdobramentos da pandemia da COVID-19 no âmbito escolar favorece, nesse sentido, um reinvestimento de nossas apostas no sujeito: no acolhimento de seus afetos, na priorização de seus saberes, na valorização dos sentidos por ele estabelecidos.

\footnotetext{
${ }^{62}$ A Fiocruz (2020a) aponta três fases de enfrentamento da pandemia, definidas como antes, durante e depois. Para cada fase existem recomendações específicas de cuidado. Cf.: Fiocruz. Saúde mental e atenção psicossocial na pandemia COVID-19 - recomendação para gestores. 2020a. Disponível em: https://efg.brasilia.fiocruz.br/ava/pluginfile.php/73432/mod resource/content/6/cartilha gestores.pdf ${ }^{63} \mathrm{Um}$ conjunto de cartilhas e vídeo-aulas sobre o tema foi disponibilizado pela Fiocruz Brasília no curso nacional de Saúde Mental e Atenção Psicossocial na COVID-19. Disponível em: https://www.fiocruzbrasilia.fiocruz.br/atualizacao-saude-mental-psicossocial-covid19/\#
} 


\section{RevistAleph}

O advento de uma crise sanitária mundial desafia nossos saberes, uma vez que nos exige criar formas de intervenção em uma realidade da qual fazemos parte intensamente, sentindo seus diversos impactos e efeitos. Como então acolher afetos no outro neste contexto que corta a todos? O principal desafio de uma intervenção no caminho da atenção psicossocial em situações de emergência, aprendemos, é justamente este: como cuidar de si e do outro, estando ambos imersos num mesmo estado de crise?

Soma-se a tal desafio as dificuldades estruturais, de acesso à comunidade escolar após a repentina exigência de distanciamento social que culminou com o fechamento das escolas em março de 2020. Diante desse contexto, duas ações se apresentaram como possíveis ao projeto Cartografia Afetiva no ano de 2020: abrir espaços de acolhimento e fortalecer nossas redes internas de apoio, com os próprios profissionais da equipe interdisciplinar do qual fazemos parte, bem como com grupos de alunos de uma escola que uma das autoras pôde acompanhar neste período.

Com a equipe interdisciplinar, fomos orientadas pela urgência de promover um espaço onde o debate técnico fosse ao mesmo tempo um canal de construção de laços, de cuidado partilhado e de mobilização de potências. Apostamos na criação partilhada de um espaço (trans)formativo de abertura franca ao sensível de cada um, como algo que poderia possibilitar em todos um resgate de nossas ferramentas subjetivas/profissionais, capaz de contribuir no atravessamento do contexto árido pelo qual estávamos todos submetidos. Foi então um investimento necessário nos adultos para que resgatássemos juntos nossa potência de escuta e de intervenção do/no campo escolar. A troca de referenciais, ferramentas criativas e intenções ético-políticas a partir do projeto Cartografia Afetiva impulsionou o desenvolvimento de ações remotas com estudantes e professores de diferentes escolas da rede de ensino. ${ }^{64}$

\footnotetext{
64 Importante destacar que a valorização do projeto, demonstrada pelos profissionais da equipe interdisciplinar participantes dos encontros, era também acompanhada pela ideia de uma complexidade que o tornava de difícil execução, o que gerou discursos de que as ações desdobradas após os encontros eram inspiradas no projeto, e não uma continuidade deste.
} 


\section{RevistAleph}

Já com os alunos, o trabalho foi realizado com o 5 ㅇ e 6 으 anos de uma escola localizada na zona sul do Rio de Janeiro. A aposta foi abrir espaços de escuta, circulação, mapeamento e acolhimento dos afetos produzidos no contexto da pandemia, a partir de encontros remotos que traziam um jogo ou dinâmica virtual como elemento disparador. Os encontros eram norteados por três eixos de mapeamento: impactos da pandemia ${ }^{65}$, memórias do distanciamento social ${ }^{66}$ e territórios afetivos ${ }^{67}$.

Dentre os pressupostos do projeto reunidos no decorrer das experiências acima descritas, destacamos - aqui separados no intuito de darmos destaque a algumas dimensões que carregam, apesar de totalmente imbricadas entre si - aqueles que mais se aproximam das diretrizes e orientações sobre o enfrentamento da pandemia fornecidas pela Fiocruz, das indicações de órgãos e entidades do campo da educação e dos preceitos do Sistema Único de Saúde e Sistema Único de Assistência Social:

a) Quanto ao processo de diagnóstico e a dimensão técnica:

Documentos norteadores de intervenção sobre situações de crise e emergência como a que estamos enfrentando na pandemia da covid-19 apontam como estratégia fundamental de intervenção, o diagnóstico da situação (IASC, 2007), destacando que as ferramentas utilizadas para tal devem sempre respeitar o contexto local e serem utilizadas apenas quando validadas por este (IASC, 2007, p.14). Este nomeado diagnóstico deve então ser um recurso a subsidiar o que são consideradas as "respostas mínimas" (IASC, 2007, p.5), ou os primeiros passos essenciais no enfrentamento da crise.

\footnotetext{
${ }^{65}$ Buscou mapear as perdas, fragilidades e possíveis reconfigurações na organização da vida (escolar, familiar, comunitária), bem como as demandas de apoio interdisciplinar.

${ }^{66}$ Pretendeu-se acessar a experiência dos estudantes no período de distanciamento social, de modo a compreender os afetos presentes, pontos de dificuldades e estratégias.

${ }^{67}$ Buscou traços do percurso individual de cada um, nas suas variadas inserções (identidade, vida escolar, familiar, comunitária), convidando a um mergulho em sua própria história, suas percepções, vínculos, olhares, redes, etc.
} 


\section{RevistAleph}

Assim sendo, tanto o diagnóstico da situação quanto o caminho e os passos de intervenção que este aponta devem primar por um sistema participativo local de monitoramento e avaliação. Todo diagnóstico situacional deve respeitar portanto aqueles a que se destina a ação final: a população local. Fazendo um recorte de leitura para nosso contexto de atuação, tomamos a noção de escuta como uma escuta contextualizada.

Vale destacar, portanto, que quando falamos da escuta da circulação dos afetos, compreendemos que escutar é também dar consequências ao que esta circulação aponta como norte de ações necessárias no campo da educação de maneira mais coletivizada, tanto no que diz respeito ao grupo cartograficamente afetado quanto a institucionalidade de suas vozes e afetos. Em outras palavras, acolher e validar o que se ouve, quando em um âmbito educacional e institucional, inclui não apenas um convite (fundamental) a uma elaboração individual, mas também dar consequências institucionais e em ato para o que esses dizeres nos apresentam como demanda e consequente intervenção da/na instituição.

b) Quanto à dimensão de pesquisa e intervenção:

Também pautada em um processo contínuo de diagnóstico (enquanto acesso às multiplicidades) e no exercício da atenção que toma a escuta como compromisso, a cartografia agrega o pesquisar e o intervir, pretendendo compor mapas móveis, que auxiliam na compreensão dos movimentos que produzem a realidade. Em outros termos, trata-se de identificar a multiplicidade de fatores que impactam o cotidiano escolar, analisando como estes se refletem nos processos de aprendizagem e vão tecendo modos de estar na escola. Tal abordagem pretende compreender as trajetórias individuais articulando-as a diferentes variáveis: o contexto institucional, territorial, político e psicossocial.

Enquanto estratégia de pesquisa, a cartografia possibilita a produção e a análise de dados, informações, situações, etc., fundamentais para a compreensão das questões 


\section{RevistAleph}

que atravessam o contexto escolar. Enquanto estratégia de intervenção, permite o desenvolvimento de ações individuais e coletivas, como atendimentos, entrevistas e oficinas, que incluem os estudantes nos processos de identificação, reflexão e atuação nas questões que os envolvem. As ações são organizadas a partir de um processo contínuo de identificação e análise das demandas que podem ser trabalhadas por estratégias lúdicas, artísticas, pela expressão e participação dos estudantes no espaço escolar, bem como daquelas que precisam de suporte da rede de serviços local.

c) Quanto às indicações ético-políticas:

Os pressupostos da cartografia afirmam como tarefa ético-política a abertura de espaços de expressão - de saberes, de alegrias, de pertencimentos, mas também de insatisfações, de fragilidades, de rompimentos, de sensibilidades reprimidas. Em outros termos, espaços para a circulação, mapeamento, validação e acolhimento da palavra, dos modos de ser e dos afetos.

Tal pretensão impõe que nos posicionemos na contramão de processos de trabalho do campo escolar que por vezes pressionam pelo abandono dos afetos, seja por não considerá-los enquanto parte integrante das funções escolares, ou por visarem intervenções técnicas supostamente neutras, compartimentadas e guiadas por protocolos universais. A centralidade da técnica pode, nesta direção, encarcerar os afetos em um saber prescritivo e em uma moral normalizadora.

Ao contrário disso e em conexão com a ideia de que o "olhar das margens permite constituir outras visibilidades e outras dizibilidades sobre qualquer tema" (FOUCAULT, 2004, p. 10), a aposta ética que aqui afirmamos consiste em reconhecer, buscando validação institucional, as perspectivas, as necessidades, os olhares e os sentidos de grupos marginalizados ${ }^{68}$ ao campo da educação. Ampliar ou dar visibilidade

\footnotetext{
68 Consideramos como grupos marginalizados não apenas sujeitos alijados dos lugares de fala ou do acesso a direitos básicos, como também todos aqueles que representam saberes e práticas consideradas menores, os saberes dominados conforme desenvolvido por Foucault (2004, p. 96).
} 


\section{RevistAleph}

ao que é potente, mas tem dificuldade de emergir; reconhecer demandas e desejos; produzir pequenos espaços de liberdade no cotidiano escolar; exercer atenção às intensidades que pedem passagem. Eis os modos pelos quais essa proposta procura se conduzir como aposta ético-política.

No contexto da pandemia da COVID-19, esta premissa ético-política se torna ainda mais premente posto que as pessoas são afetadas de formas diferentes em emergências humanitárias (IASC $\left.{ }^{69}, 2007\right)$ e que, portanto, elas requerem apoios e respostas diferentes.

\section{Considerações finais}

O contexto mundial causador de estados de fragilidade nos convoca a observar o fluxo dos nossos afetos: nossas percepções, sentimentos e as estratégias que vimos inaugurando para lidar com isso tudo. Mais do que nunca, se torna fundamental reconhecer e valorizar nossa trajetória as importantes ferramentas de que dispomos para lidar com isso tudo.

Por afeto, não entendemos apenas a expressão de sentimentos, mas também e sobretudo, as condições que impactam um campo sensível. Conforme destacado por Espinosa - de onde Deleuze também conduz sua leitura - o afeto (ou afecção) diz respeito a tudo aquilo que aumenta ou diminui nossa potência de agir (SPINOZA, 2008, p. 98). Identificar e intervir nas condições sociais e históricas que produzem sofrimentos é, assim, parte fundamental desse trabalho.

A Cartografia Afetiva se apresenta como método de abordagem para estudos da subjetividade, se constituindo como método de pesquisa-intervenção que se orienta a

\footnotetext{
${ }^{69}$ IASC é um Comitê Permanente de Interagências, estabelecido pela Assembleia Geral das Nações Unidas. Trata-se de um fórum interagências de coordenação, desenvolvimento de políticas e tomada de decisões pelos chefes executivos das principais agências humanitárias (agências da ONU, Sociedades da Cruz Vermelha e do Crescente Vermelho e consórcios de organizações humanitárias não governamentais).
} 


\section{RevistAleph}

diagramar redes, considerando as experiências de cada sujeito e suas diferentes temporalidades.

Enquanto ferramenta flexível nos temas e procedimentos, ela nos fornece subsídios para reconhecer as estratégias e ferramentas que dispomos, estabelecendo, ao mesmo tempo, novas possibilidades de trabalho, vínculos, redes de apoio, cuidado e pertencimento.

Neste sentido, o cenário imposto pela pandemia nos permite reafirmar o roteiro de preocupações fornecido pela Cartografia Afetiva, sobretudo no que diz respeito à intenção de mergulhar na geografia dos afetos como forma de trazer a experiência, fazer circular a palavra, reconstruir coletivamente, desnaturalizar, criar pontes de linguagem e travessia para a reflexão sobre si, sobre trajetórias, formas de ser, de sentir e de estar no mundo. Pensamos ser esta uma proposta conectada aos pressupostos necessários à prática educativa, que Paulo Freire tanto buscou destacar: a escuta e o diálogo não apenas como método didático, mas como fundamento próprio do trabalho de ensinar e aprender. Paulo Freire foi insistente em nos convidar a transitar dos programas rígidos para os conteúdos vivos que impactam as formas de aprender, de responder aos desafios impostos, de se vincular, de se relacionar com o outro. Para tanto, destacou a importância do falar com sujeitos de uma escuta partilhada, em detrimento do falar $a$ objetos de um discurso imposto (FREIRE, 2020). Acreditamos que o projeto Cartografia Afetiva nos tenha fornecido algumas ferramentas para dar consequência a tal convite, renovando em nós o desejo de nos aproximarmos mais para ouvir os sussurros das vozes que de tanto gritar, hoje falam mais baixo.

\section{Referências}

BRASÍLIA. Saúde mental e atenção psicossocial na pandemia COVID-19 - recomendação para gestores. Fiocruz, 2020a. Disponível em:

https://efg.brasilia.fiocruz.br/ava/pluginfile.php/73432/mod resource/content/6/cartilha ges tores.pdf

BRASÍLIA. Recomendações Gerais. Fiocruz 2020b. Disponível em: 


\section{RevistAleph}

https://efg.brasilia.fiocruz.br/ava/pluginfile.php/73427/mod resource/content/3/cartilha rec omenda\%C3\%A7\%C3\%B5es gerais.pdf

FISCHER, Rosa M. B. Foucault revoluciona a pesquisa em educação? In: FISCHER, Rosa M.B. Trabalhar com Foucault: arqueologia de uma paixão. Belo Horizonte: Autêntica Editora, 2012. p. 99-112.

FOUCAULT, Michel. Microfísica do Poder. Rio de Janeiro, Graal, 2004.

FOUCAULT. Ditos e Escritos IV: Estratégia, Poder-Saber. Rio de Janeiro, Editora Forense Universitária, 2003.

IASC, Comitê Permanente Interagências. Diretrizes do IASC sobre saúde mental e apoio psicossocial em emergências humanitárias. Tradução de Márcio Gagliato. Genebra: IASC, 2007. Disponível em: http://avipg.org/pdf/diretrizes-iasc-saude-mental-apoio-psicossocialemergencias-humanitarias.pdf.

LARROSA, Jorge. Notas sobre a experiência e o saber de experiência. Revista Brasileira de Educação, n. 19, jan./abr. 2002.

PASSOS, Eduardo; KASTRUP, Virginia; ESCÓCIA, Liliana da (orgs.). Pistas do método da cartografia: Pesquisa-intervenção e produção de subjetividade. Porto Alegre: Sulina, 2015.

RIO DE JANEIRO. Decreto no 47.247 de 13 de março de 2020. Estabelece conjunto de ações necessárias à redução do contágio pela COVID-19 - Coronavírus, e dá outras providências.

RIO DE JANEIRO. Decreto no 47.488 de 02 de junho de 2020. Institui o Comitê Estratégico para desenvolvimento, aprimoramento, e acompanhamento do Plano de Retomada, em decorrência dos impactos da pandemia da COVID-19, e dá outras providências. Anexo II

RIO DE JANEIRO. Protocolo Sanitário de Prevenção à COVID-19 para as Unidades Escolares e Creches integrantes do Sistema Municipal de Ensino do Rio de Janeiro. Disponível em: http://www.rio.rj.gov.br/dlstatic/10112/12394584/4312613/ProtocoloSanitarioSME20 21Versao1.2.pdf

FREIRE, Paulo. Pedagogia da autonomia: saberes necessários à prática educativa. 66a Ed.- Rio de Janeiro/ São Paulo: Paz e Terra, 2020.

ROLNIK, Suely. Cartografia sentimental: Transformações contemporâneas do desejo. São Paulo: Estação Liberdade, 1989.

SPINOZA, Baruch. Ética. Trad. de Tomaz Tadeu da Silva. Belo Horizonte: Autêntica, 2008.

Data do envio: $06 / 04 / 2021$

Data do envio: 07/04/2021 